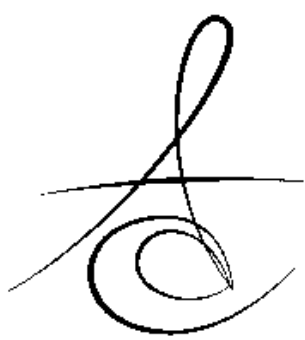

Makale Kodu/Article code: 1503

Makale Gönderilme tarihi: 28.01.2014

Kabul Tarihi: 12.03.2014

\section{AMELOGENEZİS İMPERFEKTALI BİR HASTANIN PROTETİK REHABİLITASYONU: OLGU SUNUMU}

PROSTHETIC REHABILITATION IN A PATIENT WITH AMELOGENESIS IMPERFECTA: A CASE REPORT

\author{
Dr. Sibel DİKİCİER *
}

\section{ÖZET}

Amelogenezis imperfekta (Aİ), kalıtsal mine defekti hastalığı olarak tanımlanmış olup, genellikle dişlerde mine hipoplazisi, hipomaturasyonu veya kalsifikasyonu ile karakterizedir. Bu olguda; kliniğimize başvurmuş hipoplastik tip Aİli genç erkek hastanın oral rehabilitasyonu sunulmaktadır. Estetik ve fonksiyon, tüm ağız sabit protezle düzeltilmiştir. Hastanın sonraki kontrollerinde protetik rehabilitasyonla ilgili herhangi bir patoloji saptanmamıştır.

Anahtar kelimeler: Amelogenezis imperfekta, hipoplastik tip, protetik rehabilitasyon

\section{GİRİŞ}

Amelogenezis imperfekta (AI) diş minesinin yapısını belirleyen heterojen kalıtsal bir anomali olup hem süt hem sürekli dentisyonu etkilemektedir. ${ }^{1,2}$ Nadir görülen bu anomalinin sıklığı, çalışan nüfusa ve tanı kriterlerine göre farklılık göstermekte, yaklaşık olarak 1:700 ile 1:16000 arasında değişmektedir. ${ }^{3}$ İlk kez 1890 yılında rapor edilen hastalık için, çok sayıda sınıflama bulunmaktadır ve bunlar arasında en çok kabul edilen, hastalığın genetik geçişini ve klinik özelliklerini tanımlayan Witkop'un 1989'daki sınıflamasıdır. ${ }^{4}$ Bu sınıflamaya göre 4 tane Aİ tipi ve 10 tane de alt sınıfı bulunmaktadır. Bunlar; hipoplastik tip, hipokalsifik tip, hipomature tip, son olarak hipomaturasyon ve hipoplazinin birlikte görüldüğü taurodontizm'dir.

En sık görülen Aİ şekli hipoplastik tiptir. Bu tipte, minenin yapısı normal ancak kalınlığı azdır. Parlak sarı, sert olan mine yüzeyinde çukurcuk ve fissürlere rastlanır. Radyolojik olarak dişin tüm yapıları

\section{ABSTRACT}

Amelogenesis imperfecta (AI) has been defined as a group of hereditary enamel defects. It can be usually characterized by enamel hypoplasia, hypomaturation, or hypocalcification of the teeth. This case report describes the oral rehabilitation of a young male patient referred to our clinic diagnosed with the hypoplastic type of AI. The esthetic and function was prepared with full-mouth fixed prosthesis. The recall examination revealed no pathology associated with the prosthetic rehabilitation.

Key words: Amelogenesis imperfecta, hypoplastic type, prosthetic rehabilitation

gözlemlenir, ancak mine ya incedir ya da yoktur. Dişler prepare edilmiş gibi görünür. Hipokalsifiye tipte mine, normal miktarda oluşmuştur fakat çok düşük mineralizasyona sahiptir. Yumuşaktır ve kolaylıkla dentin yüzeyinden kaldırılabilir. Dişler sürdükten sonra mekanik streslerle mine aşınır ve koyu kahverengi ya da siyah bir dentin tabakası ortaya çıkar. ${ }^{5,6}$ Hipomature tipte ise mine kristal yapısının maturasyonu ile ilgili problem vardır. Mine lekeli opak beyaz, sarıkahverengi veya kırmızı kahverengi renktedir.,

Aİ́nin hem klinik görünümü hem de kalıtsal özelliklerinin ayırt edilmesindeki zorluklara rağmen, teşhis ve tedavisi açısından, genel özelliklerin bilinmesinin yararlı olacağı bildirilmiştir. ${ }^{9}$ Aİ hastalarında sürme anomalileri, dikey boyut kaybı, zayıf dental estetik gibi durumların yanı sıra; konjenital diş eksikliği, pulpa kalsifikasyonu, açık kapanış, kuron-kök rezorbsiyonları, hipersementoz, kök malformasyonları gibi dental anomalilere de rastlanmaktadır. ${ }^{10-12}$ Günümüzde Aİli bir hastada estetik ve fonksiyonun tedavisi adeziv restorasyonlar, laminate restorasyonlar, metal destekli veya metal desteksiz sabit porselen

\footnotetext{
${ }^{*}$ Çorlu Asker Hastanesi, Diş Servisi, TEKİRDAĞ
} 
restorasyonlar ve hareketli protezler ile yapılabilmektedir. $^{13,14}$

$\mathrm{Bu}$ olgu sunumunda kliniğimize başvuran hipoplastik tip Aİli bir hastanın protetik rehabilitasyonu estetik, fonksiyonel ve psikolojik olumlu sonuçlarla beraber sunulmuştur.

\section{OLGU}

21 yaşında erkek hasta, alt ve üst dişlerindeki kahverengi lekelerden, iyi olmayan estetik görünümünden ve çiğneme yetersizliğinden şikayetle kliniğimize başvurdu. Destek dişler, sert ve yumuşak dokular, ağız içi, ağız dışı, ve radyografik muayeneyle incelendi. Ağız içi muayenede; Angle sınıf III okluzyonu olduğu, maksiller sol santral, 1. Premolar ve mandibular sağ 1 . premolar dişlerin çekildiği, diğer dişlerin mine yapısının normale göre az ve kırılgan olduğu görüldü. Posterior dişlerin okluzal yüzeylerinde aşınma mevcuttu. Dişlerde açığa çıkmış kahverengi dentin yüzeyleri ve okluz yonda önemli ölçüde dikey boyut kaybı gözlendi (Resim 1). Hastanın anamnezinde herhangi bir sistemik hastalığı olmadığı, sürekli kullandığı bir ilaç bulunmadığı tespit edildi. Klinik ve radyografik bulgular, hipoplastik tip Aİ tanısını desteklemekteydi. Hasta farklı protetik tedavi seçenekleri hakkında bilgilendirildi, "bilgilendirilmiş olur formu" alındı, üst ve alt çene için metal destekli sabit porselen restorasyonu planlandı.

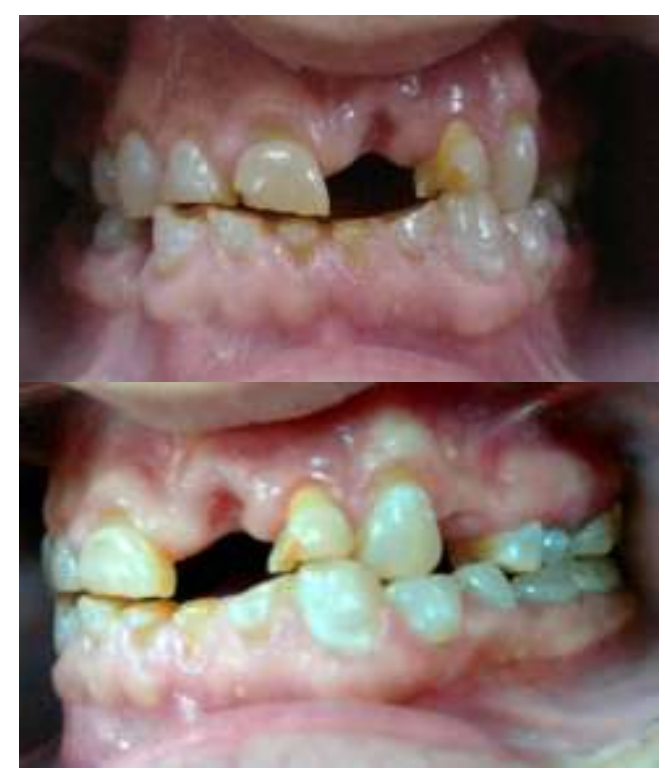

Resim 1. Tedavi öncesi ağız içi görünüm
Dikey boyuttaki azalmanın miktarının belirlenmesi amacıyla; Niswonger yöntemiyle, istirahat ve okluzal dikey boyutu belirlendi. Azalmış alt yüz yüksekliğinin, fonasyon ve estetiğin düzeltilmesi için dikey boyutun yükseltilmesine karar verildi. Üst çeneye düz yüzeyli bir stabilizasyon splinti hazırlandı ve aylık kontroller ile 3 ay kullandırıldı (Resim 2). Bu şekilde azalmış dikey boyutun temporomandibular eklem (TME) üzerindeki olumsuz etkilerinin azaltılması ve hastanın adapte olabileceği stabil bir okluzal dikey boyut sağlanması hedeflendi. Splint tedavisi ile beraber yapılan kontrollerde çiğneme kasları ve TME fonksiyonlarının normal olduğu belirlendi ve protetik tedaviye geçildi.

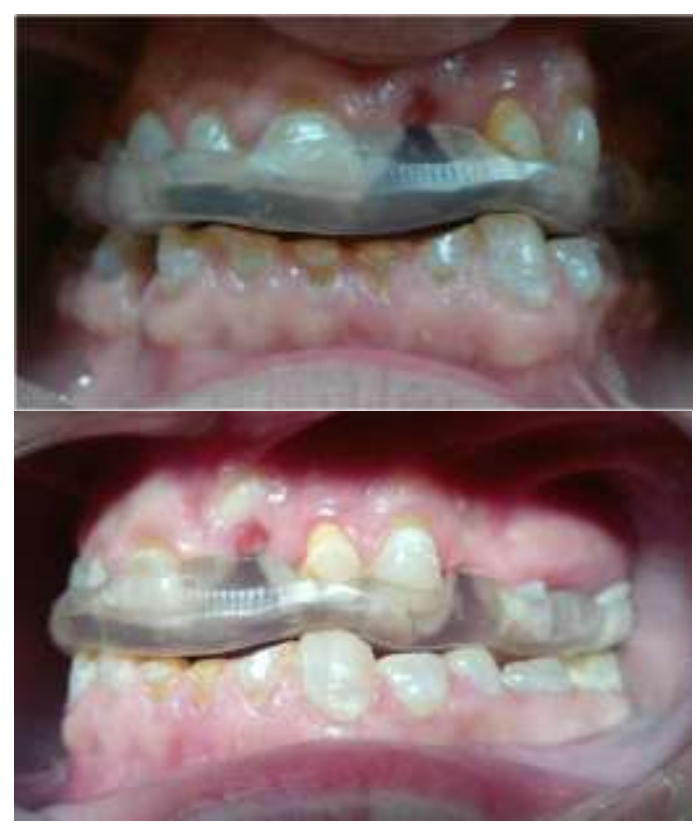

Resim 2. Dikey boyutun düzenlenmesi için hazırlanan stabilizasyon splinti

Alt ve üst dişlerin preparasyonları, metal destekli porselen restorasyonlar için, orta ve ince grenli elmas frezlerle (Finzler, Shrock\&Kimmel GmbH, Bad Ems, Germany) bıçak sırtı preparasyon ile bitirildi, preparasyon esnasında pulpası açığa çıkmış olan maksiller sol lateral dişin endodontik tedavisi yapıldı (Resim 3). Silikon esaslı ölçü maddesiyle (Reprosil, Dentsply, Australia) ölçüler alındı. Modeller elde edildikten sonra hastadan yüz arkı transferi (Artex Facebow, Northaven, CT, USA) yapıldı ve sentrik ilişki kaydı alındı, modeller tam ayarlanabilir artikülatöre (Artex Type CN, Non-Arcon, Northaven, CT, USA) 
aktarıldı. Metal destekli porselen restorasyonlar, (Ivoclar Vivadent, Schaan Liechtenstein, Germany) laboratuarda hazirlandı. Estetik ve fonksiyonel değerlendirmeyi içeren metal ve dentin provalar yapıldı. Okluzal dikey boyut belirlenen ölçüde yükseltildi ve stabil hale getirildi. Okluzyon değerlendirildi, prematür kontaktlar elimine edildi. Son olarak restorasyonlar çinko polikarboksilat esaslı siman ile (Adhesor Carbofine, Spofa Dental, Czech Republic) simante edildi (Resim 4). Restoratif işlemler sonucunda olumlu estetik ve fonksiyonel sonuçlar ile hasta memnuniyeti elde edildi (Resim 5). Hastaya düzenli olarak 6 ayda bir kontrole gelmesi önerildi.

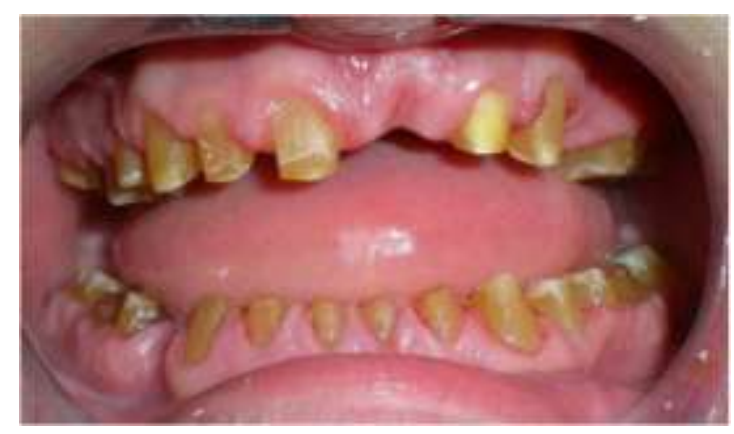

Resim 3. Dişlerin preparasyonu
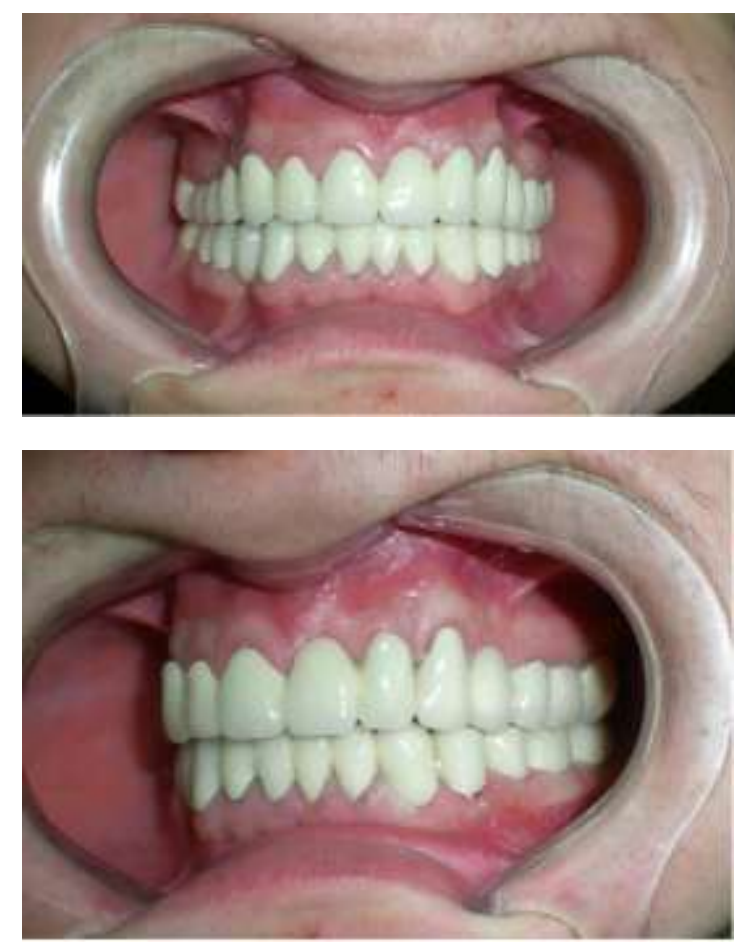

Resim 4. Tedavi sonrası ağız içi görünüm
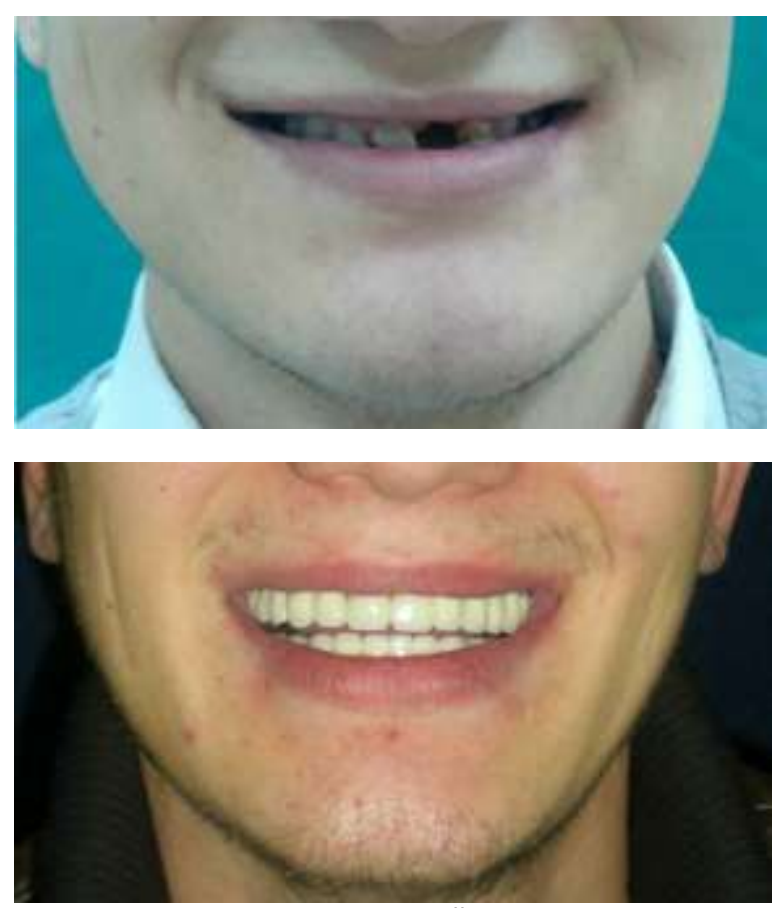

Resim 5. Tedavi öncesi ve sonrası ağız dışı görünüm

\section{TARTIŞMA}

Aİli hastalarda en önemli problemler; hızlı diş aşınmalarından kaynaklanan diş hassasiyeti, kabul edilemeyen estetik ve okluzal dikey boyut kaybıdır. ${ }^{15}$ $\mathrm{Bu}$ faktörlerden estetik ve fonksiyonel açıdan etkilenmiş olan dişlerin rehabilitasyonunda birçok tedavi alternatifi bulunmaktadır. Bu konuda tercih yapılmadan önce, hastanın yaşı, sosyo-ekonomik durumu, dişlerin etkilenme boyutu, periodontal sağlık gibi faktörler göz önünde bulundurulmalıdır. ${ }^{15,16}$ Literatürde $\mathrm{AI}^{\prime}$ nin restoratif ve protetik tedavisiyle ilgili birçok olgu sunulmaktadır. ${ }^{6-8,17,18}$ Sundell, ${ }^{3}$ hipomineralize tip AI'nin protetik tedavi ile, hipoplastik tipin ise kompozit rezin restorasyonla tedavi edilebileceğini bildirmiştir. Son yllarda estetik dişhekimliği alanındaki gelişmeler ile birlikte, özellikle dentin bağlayıcı sistemlerdeki gelişmeler ve üstün estetik özellikli kompozitlerin üretilmesi, bu tür dişlerin tedavisine olanak sunmaktadır. ${ }^{14}$ Ancak okluzal dikey boyutta kaybı olan hastalarda, kaybedilmiş okluzal uyumu yeniden oluşturmak için, overdenture protezler ve sabit kuron-köprü protezleri endikasyonu bulunmaktadır. ${ }^{14,19,20} \mathrm{Bu}$ olguda, okluzal dikey boyut kaybı ve yaygın diş aşınmaları, estetik kaygıyı da

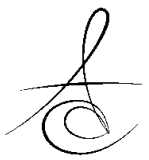


beraberinde getirdiğinden protetik olarak metal destekli sabit protezle tedavi edilmesine karar verilmiştir.

Okluzal dikey boyutun ani olarak yükseltilmesi, TME ve çevreleyen dokularda hasarlara, kas ağrılarına ve fonasyon bozukluğuna neden olabilmektedir. Bu nedenle okluzal dikey boyutun yükseltilmesi gereken olgularda, geçici restorasyonlar veya, okluzal splintlerle istenen seviyeye getirilmesi ve hasta takip edilerek semptomların durumuna göre tedavinin planlanması gereklidir. ${ }^{21} \mathrm{Bu}$ olguda, azalmış okluzal dikey boyut, fizyolojik istirahat pozisyonu belirlenerek yapılan ölçümlerle tespit edilmiş, hastaya 3 ay boyunca üst çeneye hazırlanan okluzal splint uygulanarak semptomlarının takibi yapılmıştır. Bu sürenin sonunda semptomların iyileşmesiyle birlikte protetik işlemlere başlanmıştır.

Tam ayarlanabilir artikülatörler, alt çenenin lateral hareketlerinin, interkondiler mesafenin, kondil yolu eğiminin belirlenmesine ve yüz arkı transferine imkan sağlayan sistemlerdir. ${ }^{22} \mathrm{Bu}$ olguda, yüz arkı transferi yapılarak hastanın alt çene hareketleri tam ve doğru olarak tam ayarlanabilir artikülatöre aktarılmış, okluzyonda eksentrik hareketlerdeki erken temaslar ve tüberkül çatışmaları elimine edilmiştir. Sonuç olarak; sabit restorasyonla tedavi edilen hipoplastik tip AI'li hastada, tüm estetik ve fonksiyonel beklentiler karşılanmıştır.

\section{KAYNAKLAR}

1. Aldred MJ, Savarirayan R, Crawford PJM. Amelogenesis imperfecta: a classification and cataloque for tht 21st century. Oral diseases 2003;9:19-23.

2. Sanchez-quevedo MC, Ceballos G, Garcia JM, et al. Dentine structure and mineralization in hipocalcified amelogenesis imperfecta: a quantitative $\mathrm{x}$-ray histochemical study. Oral diseases 2004;10:94-8.

3. Sundell S, Koch G. Hereditary amelogenesis imperfecta. Epidemiyology and clinical classification in a Swedish child population. Swed Dent J 1985;9:157-169.

4. Witkop CJ. Amelogenesis imperfecta, dentinogenesis imperfecta and dental dysplasia revisited:Problems in classificiation. J Oral Pathol 1989;17:547-53.
5. Dönmez N, Ünlü N. Amelogenezis imperfektalı hastalarda anterior dişlerin kompozit rezinle restorasyonu: olgu sunumu. CÜ Diş Hek Fak Derg 2005;8:105-9.

6. Koyutürk A, Kahvecioğlu $F$, Rener $Y$, Gökalp A. Geçici over-denture protezlerle rehabilite edilen amelogenezis imperfekta: Olgu sunumu. CÜ Diş Hek Fak Derg 2006;9:41-5.

7. Gisler V, Enkling N, Zix J, Kim K, Kellerhoff NM, Mericske-Stern R. A multidisciplinary approach to the functional and esthetic rehabilitation of amelogenesis imperfecta and open bite deformity: a case report. J Esthet Restor Dent 2010;22:282-96.

8. Alnıaçık G, Seçilmiş A, İnan Ö. Amelogenezis imperfektalı bir hastanın estetik ve fonksiyonunun tedavisi. SÜ Diş Hek Fak Derg 2009;18:94-7.

9. Witkop CS; Kuhlmann W, Sauk J. Autosomal recessive pigmeted hypomaturation amelogenesis imperfecta. Oral Surg Oral Med Oral Pathol 1973;36:367-82.

10. Petters $E$, Cohen M, Altini M. Rough hypoplastic amelogenesis imperfecta with follicular hyperplasia. Oral Surg Oral Med Oral Pathol 1992;74:87-92.

11. Nel JC; Pretorius JA, Weber A. Restoring function and esthetics in a patient with amelogenesis imperfecta. Int J Prosthodontics Restorative Dent 1997;17:479-83.

12. Seow WK. Clinical diagnosis and management strategies of amelogenesis imperfecta variants. Pediatr Dent 1993;15:384-93.

13. Oya K, Nalbandian J, Noikura T. Autosomal recessive rough hypoplasticamelogenesis imperfecta. A case report with clinical, light microscobic, radiographic and electron microscobic observations. Oral Surg Oral Med Oral Pathol 1988;65:449-58.

14. Şengün A, Özer F. Restoring function and aesthetics in a patient with amelogenesis imperfecta: a case report. Quintessence Int 2002;33:199-204.

15. Siadat $H$, Alikhasi $M$, Mirfazaelian $A$. Rehabilitaiton of a patient with amelogenesis imperfecta using all ceramic crowns: a clinical report. J prosthet dent 2007;98:85-8. 
16. Peumans $M$, Van Meerbeek $B$, Lamrechts $P$, Vanharle G. Porcelain veneers: a review of the literature. J Dent 2000;28:163-77.

17. Atasu M, Biren S, Mumcu G. Hypocalficication type Amelogenesis imperfecta in permanent dentition in association with heavily worn primary teeth, gingival hyperplasia, hypodontia and impacted teeth. J Clin Pediatr Dent 1999;23:11721.

18. Tulga F. Bir olgu nedeniyle amelogenezis imperfekta: kalıtım şekli, klinik, histolojik bulguları ve tedavisi. AÜ Diş Hek Fak Derg 1992;19:169-74.

19. Köroğlu A, Ekrem O, Kurtoğlu C. Farklı tip amelogenezis imperfektalı hastaların protetik rehabilitasyonu: iki olgu sunumu. AÜ Diş Hek Fak Derg. 2012;5:34-9.

20. Sandallı N, Gürsoy T, Gürsu S. Amelogenesis imperfekta: Bir olgu nedeniyle klinik histolojik tanımı ve tedavisi. İÜ Diş Hek Fak Derg 1989;23:195-200.

21. Çalıkkocaoğlu S. Tam protezler Cilt 1. 4. Baskı. Ankara; Özyurt:2004.p.272.

22. Edgar NS. The history of articulators: A Perspective on the early years. Part II. J Prosthodont 2000;9:110-2.

\section{Yazışma Adresi}

Dr. Sibel DİKİCİER

Çorlu Asker Hastanesi, Diş Servisi, 59186, TEKİRDAĞ

Tel: +902826501051

Fax: +902826521846

e-mail: dtsibel@hotmail.com

23. 